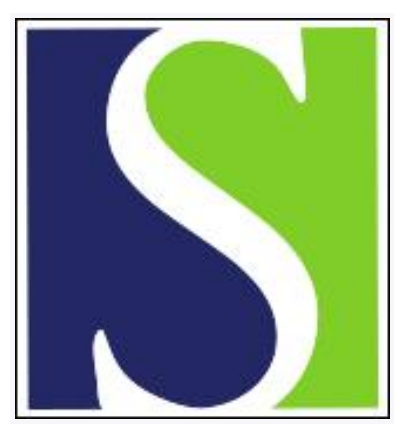

Scand J Work Environ Health 1990;16(6):406-410

https://doi.org/10.5271/sjweh.1769

Issue date: 01 Dec 1990

Estimates of new compensated cases of occupational diseases in Finland in 1977-1983.

by Alho JM, Vaaranen V, Vasama M

Affiliation: Institute for Environmental Studies, University of Illinois, Urbana-Champaign 61801.

This article in PubMed: www.ncbi.nlm.nih.gov/pubmed/2149469

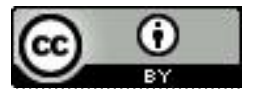




\title{
Estimates of new compensated cases of occupational diseases in Finland in 1977-1983
}

\author{
by Juha M Alho, PhD, ${ }^{1}$ Vesa Vaaranen, MD, ${ }^{2}$ Marja Vasama ${ }^{2}$
}

\begin{abstract}
ALHO JM, VAARANEN V, VASAMA M. Estimates of new compensated cases of occupational diseases in Finland in 1977-1983. Scand $J$ Work Environ Health 1990;16:406-10. The increase in the new cases of occupational disease reported in Finland in 1977-1983 has been analyzed. First, the technical nature of the concept of occupational disease as used in the context of compensation insurance is described and a disability grading for the severity of occupational diseases is presented. It is then shown, with the use of a stratified probability sample, that the fraction of compensated cases has remained roughly constant during the study period. However, evidence is presented indicating that the severity of the cases compensated in 1977-1983 has, on the average, decreased.
\end{abstract}

Key terms: accident insurance, data bases, labor protection.

In Finland statutory measures for labor protection go back as far as 1889 . Employers were then required to provide industrial workers with sufficient amounts of clean air, construct fire escapes, and so forth. In 1895 the first statutory accident insurance system was established. The employers were required to take out insurance for their workers from a private insurance company. The compensation payable was connected with the degree of disability and the employee's salary. Essentially the same principles of insurance are still in force today.

The concept of occupational disease appeared first in the statutes of 1925. It referred to diseases caused by the production and handling of such substances as lead and mercury. By 1939 the list of substances had been broadened to include such agents as arsenic, manganese, inorganic alkalis, chromates, and benzene. At the same time other factors, such as radiation, acoustic energy, chafing by a tool, and vibration, were accepted as potential causal factors for an occupational disease.

The present Occupational Disease Act came into force in 1988. The previous act from 1967 had already broadened the concept of occupational disease to include all diseases caused by physical, chemical, or biological factors at work. The new act and the associated ordinance provide a list of 45 such factors with typical forms of disease. Tenovaginitis and humeral epicondylitis were also specifically included as occupational diseases. Earlier they had been compensated as

\footnotetext{
${ }^{1}$ Institute for Environmental Studies and Department of Statistics, University of Illinois at Urbana-Champaign, Urbana, Illinois, United States.

2 Institute of Occupational Health, Helsinki, Finland.
}

Reprint requests to: Dr J Alho, Institute for Environmental Studies, 1101 W Peabody Dr, Urbana, IL 61801, USA. occupational injuries. The primary principle for the assessment causality between occupational factors and disease is that occupational exposure must be sufficient to cause the disease.

A consequence of this historical development is that the Finnish concept of occupational disease has a distinctly technical meaning in insurance. The causal factors have slowly evolved from a narrow list of chemical factors to encompass, in principle, all chemical, physical, and biological factors. - Psychological factors remain excluded.

The domain to which the concept applies has evolved from workers in traditional manufacturing to essentially all employees. Farmers were excluded from the system until 1981 (unless they had voluntary insurance), when a comprehensive system was established for farmers.

The gradual evolution of the legal concept of occupational disease is one basis for believing that a widening of the scope of diseases reported as occupational diseases might take place even when major changes in the legislation do not occur.

The number of new cases of occupational disease rose in Finland from 4639 in 1977 to 5904 in 1983. In 1989 a total of 7217 cases were reported. The cause of the increase is thought to be improved reporting. When both physicians, workers, and employers become aware of the occupational factors in the etiology of diseases, new cases will be discovered. It is possible that, as a by-product of the increased interest, some of the newly reported cases have only a tenuous connection with work, and they may be rejected by the insurance companies. It is also possible that better diagnostics lead to the discovery of new, milder cases of disease which would have been overlooked in the past. The main purpose of this paper was to consider both of these possibilities in an analysis of sample data from the years $1977-1983$. 


\section{Materials and methods}

\section{Disability grading of occupational diseases}

To describe the severity of occupational diseases, a system has been devised for grading based on the medical prognosis of the disease and the type of disability it causes. [See the International Classification of Impairments, Disabilities, and Handicaps (1).] Such a grading is always somewhat arbitrary since the severity of a disease is a concept with many other dimensions as well. However, we feel that the following five grades, listed from the most severe to the least severe, are relatively well discernible in the Finnish pattern of occupational diseases. We have created the grades by combining classes of diagnoses of the International Classification of Diseases (eighth revision) as adapted by the Institute of Occupational Health.

Grade I. Diseases which cause disabilities which progressively worsen even without further exposure or create a necessity to change occupation form grade I. The most common occupational diseases belonging to this class are allergic alveolitis, silicosis, asbestosis, and chronic intoxications caused by carbon disulfide or solvents. This grade also includes malignancies caused by occupational factors.

Grade II. Diseases causing permanent disability or a need to change occupation comprise grade II. By far the most common disease belonging to this grade is noise-induced hearing loss. Cases involving difficulties to hear normal speech are included. Other cases belonging to grade II are all but the mildest cases of vibration syndrome, allergic asthma, allergic rhinitis, allergic contact eczema, and other pneumoconioses besides those in grade I.

Grade III. Diseases with permanent mild disability are classed as grade III. About a third of all cases of noise-induced hearing loss are mild in the sense that the patient hears, for example, normal speech without difficulty at the time of the diagnosis. They form the majority of cases in this class. The mildest cases of diseases otherwise included in grade II are also included in grade III. The criterion of mildness is that the disease causes an inconvenience of at most "class 2." In such a case, for example, asthma would be so mild as not to cause shortness of breath in climbing stairs or an eczema would be symptomless by simple preventive measures.

Grade IV. Diseases with severe temporary disability or a sick leave of at least three weeks comprise grade IV. Such diseases as tuberculosis, salmonellosis, hepatitis infectiosa, temporary paresis caused by unusual work postures (eg, paresis nervi peronei caused by strawberry picking in a kneeled position) are included according to the degree of severity. The length of the sick leave determines whether such diseases as tendovaginitis, peritendinitis, epicondylitis, infection erysipeloidis, and toxic eczema are included.

Grade $V$. Diseases with mild temporary disability or a sick leave of less than three weeks belong to grade $\mathrm{V}$. The degree of disability determines whether other infectious diseases besides those already mentioned, various respiratory symptoms caused by irritants, metal fume fever, and conjunctivitis photoelectrica ("welder's eye") are included. The length of the sick leave is used with the same diagnoses as in grade IV. The vast majority of the cases in grade $\mathrm{V}$ are included by the latter criterion.

\section{Data and sampling procedures}

The Finnish Register of Occupational Diseases is kept by the Institute of Occupational Health in Helsinki. It obtains its data from essentially two sources. Well over half of the new cases come from private insurance companies. This channel has been in operation since 1964, and it is based on an agreement between the Federation of Accident Insurance Institutions and the Institute of Occupational Health. Some differences in the reporting practices of the different companies have been known to exist. For example, some may report cases before a compensation decision is made, others after the decision, and yet others may not report rejected cases. The other major channel of information was statutorily established in 1975. At that time physicians were required to report all suspected occupational diseases to the National Board of Labor Protection, which delivers the data to the Register. Unfortunately, physicians often neglect to make such reports. Approximately $40 \%$ of the cases coming to the Register of Occupational Diseases come through the insurance companies only. One reason for the negligence may be that reporting is viewed as a nuisance not directly contributing to the welfare of the patient. A small number of cases comes to the Register also directly, from the physicians of the Institute of Occupational Health - For more details about the data system, see references 2 and 3 .

Finnish statistics on occupational diseases are compiled by the year of reporting rather than the year of occurrence. This use speeds up the publication of the data. However, at the time of reporting, the compensation decision is not available for approximately half of the cases. In about half of the remaining cases the compensation decision will be given to the Register one or two years later. However, for the time period 1977-1983, these decisions were only marked in the manual register, and no definite estimates about their number exist. Moreover, for the remaining quarter of the total data, the compensation decisions remain unknown.

To obtain estimates of the acceptance rate, and to collect the sometimes missing information about the 
severity of the cases, we took a stratified probability sample (4) of that part of the Register material for which the data were incomplete. Overall, there were 34520 cases reported to the Register. In 18116 cases $(52 \%)$ either the compensation decision or inconvenience class or length of sick leave was missing. The base population for sampling consisted of these 18116 . The sample was stratified first by year and within each year by disability grading (grade I versus other grades) so that grade I was guaranteed to have adequate representation in the sample. The total sample size was 1877. The sampling fractions varied from stratum to stratum with the goal of achieving the same level of estimation error for each year.

Three methods were used to obtain information for the cases in the sample. First, the cases were searched from the manual register. Second, for 1982-1983, the remaining cases were linked to the computerized data base of the Federation of Accident Insurance Institutions, which was started in 1982 . Third, all the reports that remained incomplete after steps one and two were sent to the insurance companies to which they were known or believed to belong. As a result, the data were completed for $79.5 \%$ of the sample. This figure translates into an approximately $10 \%$ gap in the original data. In the discussion of the data we have presented two analyses. First, we assumed that all the missing data correspond to rejections. Second, they were assumed to correspond to positive compensation deci-

Table 1. Number of new cases of occupational disease reported to the Finnish Register of Occupational Diseases in $1977-1983$ and the lower-bound estimates of the fraction (\%) of accepted cases, its corresponding $95 \%$ lower confidence limit, the upper-bound estimates of the fraction of accepted cases, its corresponding $95 \%$ upper confidence limit, and the fraction of accepted cases out of the cases for which the compensation decision is known.

\begin{tabular}{|c|c|c|c|c|c|c|}
\hline Year & $\begin{array}{c}\text { Number } \\
\text { of } \\
\text { cases }\end{array}$ & $\begin{array}{l}\text { Lower } \\
\text { bound }\end{array}$ & $\begin{array}{l}95 \% \\
\text { lower } \\
\text { limit }\end{array}$ & $\begin{array}{l}\text { Upper } \\
\text { bound }\end{array}$ & $\begin{array}{l}95 \% \\
\text { upper } \\
\text { limit }\end{array}$ & $\begin{array}{l}\text { Accepted/ } \\
\text { known }\end{array}$ \\
\hline $\begin{array}{l}1977 \\
1978 \\
1979 \\
1980 \\
1981 \\
1982 \\
1983\end{array}$ & $\begin{array}{l}4639 \\
4465 \\
4444 \\
4472 \\
5231 \\
5365 \\
5904\end{array}$ & $\begin{array}{l}79.4 \\
78.5 \\
76.9 \\
78.1 \\
73.6 \\
74.3 \\
79.1\end{array}$ & $\begin{array}{l}76.2 \\
75.3 \\
73.6 \\
74.9 \\
70.3 \\
71.1 \\
76.1\end{array}$ & $\begin{array}{l}90.9 \\
90.6 \\
87.4 \\
89.7 \\
87.7 \\
84.3 \\
87.3\end{array}$ & $\begin{array}{l}93.1 \\
92.6 \\
89.8 \\
91.9 \\
89.9 \\
86.8 \\
89.6\end{array}$ & $\begin{array}{l}89.7 \\
89.3 \\
85.9 \\
88.3 \\
85.6 \\
82.6 \\
86.2\end{array}$ \\
\hline
\end{tabular}

sions. The true values fall inbetween these two estimates.

We would like to point out that the use of a random sampling procedure is particularly useful in this application. Since much of the work is the extremely tedious manual-matching of incomplete records, it would have been impossible to ask the insurance companies to check all 18116 cases of the base population. Even if this manual check could have been made, it is possible that the effort spent in locating individual records would have been less and would have resulted in a larger fraction of incomplete cases than now in our sample - and consequently in a larger margin of bias in the estimates.

\section{Results}

\section{Trends in compensation}

Table 1 contains our sample-based estimates of the fraction of Register cases receiving compensation. Four estimates are given. "Lower bound" is the point estimate obtained from the stratified sample on the assumption that all missing cases are rejects. The corresponding lower confidence interval, which takes into consideration the sampling variability of the stratified sample, is given by the "95\% lower limit." "Upper bound" is the point estimate obtained on the assumption that all missing cases were accepted, and the "95 \% upper limit" gives the corresponding upper $95 \%$ confidence limit. It can be seen that the difference between the "upper bound" and the "lower bound," which corresponds to the fraction of missing values, is slightly over $10 \%$ annually. The "accepted/known" column gives the fraction of accepted cases out of the cases for which a compensation decision was known. An approximate $95 \%$ confidence interval for this ratio is $\pm 3 \%$ for each year. It can be seen that $85-90 \%$ of the cases with known compensation decisions have been accepted.

\section{Trends in severity}

As far as the "accepted material" (ie, those cases that were accepted when reported to the Register originally or those that were found to have been accepted in

Table 2. Estimated number of cases of occupational disease accepted in Finland in 1977-1983 by disability grade.

\begin{tabular}{lcccccr}
\hline Year & $\begin{array}{c}\text { Total } \\
(\mathrm{N})\end{array}$ & $\begin{array}{c}\text { Grade Ia } \\
(\mathrm{N})\end{array}$ & $\begin{array}{c}\text { Grade IIa } \\
(\mathrm{N})\end{array}$ & $\begin{array}{c}\text { Grade III } \\
(\mathrm{N})\end{array}$ & $\begin{array}{c}\text { Grade IVa } \\
(\mathrm{N})\end{array}$ & $\begin{array}{c}\text { Grade Va } \\
(\mathrm{N})\end{array}$ \\
\hline 1977 & 3681 & 75 & 1607 & 383 & 598 & 1017 \\
1978 & 3506 & 89 & 1345 & 472 & 378 & 921 \\
1979 & 3416 & 87 & 1376 & 376 & 584 & 993 \\
1980 & 3492 & 73 & 1264 & 448 & 593 & 1114 \\
1981 & 3851 & 106 & 1387 & 634 & 433 & 1291 \\
1982 & 3986 & 84 & 1574 & 669 & 464 & 1195 \\
1983 & 4675 & 116 & 1695 & 791 & 704 & 1368 \\
\hline
\end{tabular}

a For a definition of the grade, see the Materials and Methods section. 
the sample study) is concerned, 1161 cases in the sample of 1877 were accepted. Among the accepted cases were 22 known to belong either to disability grade II or III, but for which the inconvenience class remained unknown. They were allocated into grades II and III in the proportions these classes had without them. Similarly, 43 cases with no sick leave data were allocated to grades IV and V. Table 2 gives the resulting annual estimates of accepted cases, among those reported to the Register, by disability grading.

Half of the overall increase in the accepted cases came from grade III (primarily mild cases of hearing loss) and grade V (mild cases of musculoskeletal diseases caused by repetitive or monotonous work). However, there have been increases in other grades as well, including grade I. Although many serious occupational diseases (eg, asbestosis, silicosis, and chronic intoxications caused by carbon disulfide) have declined over the years, new cases of allergic alveolitis have been found in agriculture, and these new cases have increased the numbers of grade $I$.

\section{Discussion}

Table 1 shows that the fraction of missing values has been approximately $10 \%$ annually. Even though part of the missing data has very likely been accepted and part rejected, we believe that most of the cases are such that they have never been brought to an insurance company. As such they should be interpreted as neither accepted nor rejected.

A word of caution is in order. Cases of occupational disease probably exist that have not been reported through either channel to the Register. So-called dual estimation, or capture-recapture method (5), leads to estimates of as many as $55 \%$ more cases not reported through either channel in Finland in 1981 (6). The estimate does not change if one controls for possible population heterogeneity due to age, in addition to diagnosis and sex (7). If the reporting practices in Finland were similar to those in Sweden, over twice as many cases would be reported (8). Consequently, it is prudent to assume that our estimates of compensation rates pertain only to the cases reported to the Register. For example, on the basis of our data we cannot claim that the probability of rejection of a compensation claim for an occupational disease would be approximately $10 \%$ in Finland, as one might be tempted to conclude from the "upper estimates."

The initial decline in the reports from 1977 to 1978 or 1979 shown in table 1 is probably caused by the fact that the statutorily established second information channel had began to operate in 1975. Consequently, there was a large pool of cases that had to be reported according to new rules. As the initial pool dwindled, a normal period of development resumed in the late 1970s. The first two columns of table 1 do not show any indication that the fraction of accepted cases would have changed during 1977-1983. There is, however, some indication of an increase in the number of rejected cases, as can be seen from the columns "upper bound" and "95 \% upper limit," but it is not nearly sufficient to explain the increase in reported incidence.

There is more year-to-year variation in table 2 than one might expect. If work conditions, disease diagnostics, and reporting practices would have remained constant in 1977-1983, then the column entries of table 2 could be viewed approximately as independent Poisson counts, with variance estimates equal to the observed values. A hypothesis that the column counts come from the same Poisson distribution is refuted for each column (details not shown).

As has already been noted, the increases in the accepted cases of grade I, shown in table 2, are primarily due to newly found cases of allergic alveolitis. It is perhaps useful to note that allergic alveolitis in agriculture began to appear in the Register years before the introduction of the comprehensive insurance for farmers in 1981. However, during the earlier years, a very small number of the reported cases were compensated as occupational diseases because only a few farmers had voluntary insurance. Had the Register limited its material to accepted cases only, we would have had little information about the frequency of this diagnosis in those earlier years.

\section{Concluding remarks}

In this paper we have presented sample-based estimates of the acceptance rates of cases of occupational diseases reported to the Finnish Register of Occupational Diseases in 1977-1983. The fraction of accepted cases appears to have remained at approximately $80 \%$ during this time. The fraction of rejected cases has been less than $10 \%$. We suspect the remaining cases may not have been evaluated at all in insurance companies as occupational diseases. We also studied the severity of the accepted cases and found evidence that the increase in accepted cases was partly due to the fact that milder cases are both reported and accepted and partly due to better diagnostics and reporting, as in the case of allergic alveolitis. Although the legal concept of occupational disease has remained similar over the years, a de facto broadening of the concept has been slowly taking place.

\section{Acknowledgments}

The authors would like to thank the Finnish Federation of Accident Insurance Institutions, especially $\mathrm{Mr}$ $\mathrm{J}$ Lehmus, and the many affiliated insurance companies, whose efforts made possible the sampling study on which much of our material was based. We would also like to thank Mr J Toikkanen for his help with the data processing. 


\section{References}

1. World Health Organization. International classification of impairments, disabilities, and handicaps. Geneva: World Health Organization, 1980.

2. Vaaranen V, Vasama M, Alho J. Occupational diseases in Finland in 1982. Helsinki: Institute of Occupational Health, 1983. (Reviews 8.)

3. Vaaranen V, Vasama M, Alho J. Occupational diseases in Finland in 1984. Helsinki: Institute of Occupational Health, 1985. (Reviews 11.)

4. Cochran WG. Sampling techniques. 3rd ed. New York, NY: John Wiley \& Sons, 1977.

5. Seber GAF. The estimation of animal abundance. 2nd ed. London: Griffin, 1982.

6. Alho J. Effects of population heterogeneity on dual registration estimates. Paper presented in the 11 th Nordic Conference on Mathematical Statistics in Uppsala, Sweden, June 1986.

7. Alho J. Logistic regression in capture-recapture models. Biometrics (in press).

8. Nordiska Ministerrådet. Anmälda Arbetssjukdomar i Norden 1985. Copenhagen: Nordiska Ministerrådet, 1988. (Nord 1988:61).

Received for publication: 20 December 1989 